\title{
Assessment of mortality rate and its relation to off-hours and holidays in patients admitted to the CCU of a Noor general hospital
}

\author{
Shahram Ala ${ }^{1^{*}}$, Abbas Alipour ${ }^{2}$, Fatemeh Faramarzi ${ }^{1}$, Khadijeh Farkhondeh ${ }^{3}$ \\ ${ }^{1}$ Department of Clinical Pharmacy. Faculty of Pharmacy, Mazandaran University of Medical Sciences, Sari, Iran \\ ${ }^{2}$ Thalassemia Research Center, Department of Community Medicine, Faculty of Medicine, Mazandaran University of Medical \\ Sciences, Sari, Iran \\ ${ }^{3}$ Imam Khomeini General Hospital, Mazandaran province, Noor, Iran
}

Received: Nov 15, 2014, Revised: Jan 12, 2015, Accepted: Jan 21, 2015

\begin{abstract}
Despite the reduction of mortality rate in the past years, coronary artery diseases (CADs) are the main reason of death in the world. Many factors including changes in nurses and medical staffs, numbers of beds influence the mortality rate of patients admitted in holidays and night time. The objectives of this study were to clarify the association between mortality rate and off-hours and holidays in patients admitted to the cardiac care unit (CCU) of Noor General Hospital. This is a retrospective study of 186 hospitalized patients in CCU that suffered cardiac arrest during 10 years. Patients 'data was gathered in a questionnaire including information about sex, date and cause of hospitalization and cardiac arrest, CPR duration, admission in working hours, off-hours and holidays. Data showed that patients were between the ages of 21 to 88 years old $(66.92 \pm 52.12)$, and 92 patients $(50 \%)$ were female. Time of admission of 146 deceased patients (79.5\%) and time of CPR of 145 of them (78.9\%) were in off- hours and holidays. Patients who had died of pulmonary embolism were admitted in the evenings and holidays. Cardiac arrest and CPR of hospitalized patients diagnosed with cardiogenic shock and chronic renal failure were in the evening shift and holidays, too. Higher mortality of CCU patients admitted during nights, evening hours, and holidays or when CPR were performed on them during these times showed that patient care and diagnostic and treating procedures were not performed effectively; and this issue could be due to the fewer number of physicians, nurses or fatigue of staffs at night hours.
\end{abstract}

Keywords: Mortality, CCU, holidays, off- hours, CPR

Pharm Biomed Res 2015; 1(1): 55-62

DOI: 10.18869/acadpub.pbr.1.1.55

\section{Introduction}

Despite the reduction of mortality rate in the past years, Coronary Artery Diseases (CADs) are the main reason of death in the world (1). Due to increase of life span in IRAN and the fact that CADs are more likely to happen in old age, they have become the main reason of mortality in the country. Changes in sympathetic activity, platelet aggregation, fibrinogen and antithrombin function in early morning hours causes higher incidence of acute myocardial infarction (AMI) and more patients will be admitted in holidays and night time (2). Care of critical patients in special units of hospitals is very important because these patients'respiration and nutrition conditions are not good, so real time and intensive monitoring is needed. Given that faster the treatment of AMI starts better long term results can be achieved, admission and treatment in shortest time is needed. Many factors including changes in nurses and medical staff, number of beds, intensity of disease and comorbidities influence the mortality rate of these patients. Researches show that well rested physicians had better functions that result in better diagnostic and analysis of data and in the end, higher patient safety. Therefore limiting the work hours of physicians will give better results (3). Studies suggest that mortality of critical patents increase in holidays and night times (4-11). A recent study on patients admitted with worsening heart failure shows no difference in mortality rate of

"E-mail: sh204ala@yahoo.com 
hospitals on week days and weekends (12). The objectives of this study were to clarify the association between mortality rate and off-hours and holidays in patients admitted to the CCU of Imam Khomeini Hospital of Noor city in north of Iran.

\section{Materials and methods}

This is a descriptive and retrospective study on 186 hospitalized patients in cardiac care unit (CCU) of Imam Khomeini general hospital of Noor city , Mazandaran province, located in north of Iran. This governmental hospital has 150 beds includes 8 of CCU beds. These patients were expired with cardiac arrest during 10 years from 24 March of 2003 to 26 august of 2013. Patients Data was gathered in a questionnaire including sex, date of hospitalization, cause of hospitalization, co morbidities, cause and time of cardiac arrest, CPR duration, working hours, off hours and holidays In order to compare the association between mortality rate and admission and CPR time, patients divided into 4 groups: a; morning shift of week days b; evening shift of week days c; morning and evening shifts of holidays $d$; night shift of week days and holidays. The Morning Shift in this hospital started from 8 A.M to 2 P.M, the evening shift from 2 P.M to 8 P.M and the night shift from 8 P.M to 8 A.M. Week days are from Saturday to Thursday and Friday was the weekend; also other official holidays were considered as a holiday. The morning shifts were considered working hours and other shifts were non working hours.

Because the study was retrospective, some data such as time of admission of 7 patients were not available.

\section{Statistical analysis}

Descriptive baseline characteristics for groups of study comparisons were tabulated as mean \pm standard deviation (SD) or as percentages. Association between the reason of hospitalization and comorbidities with time of admission and CPR were evaluated using chisquare or Fisher-exact test and for continuous data were statistically analyzed using student ttest in univariate analysis. All factors with a significance of $\mathrm{p}<0.2$ were entered into a binary backwards-stepwise logistic regression model. A p value of 0.05 or less was considered statistically significant and $p$ value of less than 0.1 considered marginally statistically significant. Data were analyzed using IBM SPSS statistics version 16 (Chicago, USA).

\section{Results}

In This Study 184 expired patients in the CCU of Imam Khomeini Hospital of Noor city during 2003-2013 were studied based on time of admission, CPR and other factors. Their age ranged from 21 to $88 \mathrm{yr}$ with a mean age of 66.92 $\pm 52.12 \mathrm{yr}$ and $92(50 \%)$ were male. Time of admission of 146 expired Patients $(79.5 \%)$ and time of CPR of 145 of them $(78.9 \%)$ were in OffHours and holidays. Additional demographic information, reason of hospitalization and co morbidities of expired patients according to different times of admission is in table 1 and according to times of CPR is in table 2 .

As shown in table 1, Relative frequency of expired patients with AF (as the reason of hospitalization) in the morning shifts of week days is more than other shifts and the difference observed between admitted groups in different shifts were marginally statistically significant ( $p$ $=0.09)$. The relative frequency of expired patients with different comorbidities in night shift admissions is more than other shifts but only the difference observed in relative frequency of expired patients with diabetes in night shift compare to other shifts was statistically significant $(\mathrm{P}=0.04)$. Table 2 shows that the CPR of expired patients with UA and cardiogenic shock (as the reason of hospitalization), CADs, apnea and CRF (as the comorbidity diseases) were more occurred in night shift than other shifts $(\mathrm{p}<0.1)$. A multivariable binary logistic regression model revealed that after adjusting of other variables expired patients with pulmonary emboli (PE) (as the cause of hospitalization) have greater risk of admission in off-hours and holiday times than morning shifts( $\mathrm{OR}=3.32 ; 95 \% \mathrm{CI}$ : 1.11-9.94) (table 3). However multivariable binary logistic regression model revealed that after adjusting of other variables expired patients with cardiogenic shock (as the cause of admission) $(\mathrm{OR}=3.3$; 95\% CI: $1.53-7.14), \mathrm{CRF}$ (as the comorbidity diseases) $(\mathrm{OR}=4.78 ; 95 \% \mathrm{CI}$ : $1.51-15.15)$ and asystole (as the cause of death) $(\mathrm{OR}=3.08$; 95\% CI: 1.34-7.09) have greater risk of CPR in off-hours and holiday times than morning shifts (Table 4).

\section{Discussion}

This study shows that Among the CCU patients of Imam Khomeini Hospital of Noor that suffered cardiac arrest in 10 years period, time of 
Table1 Distribution of cause of admission and underlying disease of expired patients in CCU in different time of admission

\begin{tabular}{|c|c|c|c|c|c|}
\hline \multirow[b]{2}{*}{ Parameters } & \multicolumn{4}{|c|}{ Admission time } & \multirow[t]{2}{*}{$P$ value } \\
\hline & $\begin{array}{c}1 \\
(\mathrm{~N}=38)\end{array}$ & $\begin{array}{c}2 \\
(N=37)\end{array}$ & $\begin{array}{c}3 \\
(N=22)\end{array}$ & $\begin{array}{c}4 \\
(\mathrm{~N}=80)\end{array}$ & \\
\hline $\begin{array}{l}\text { Age (year) } \\
\text { Mean } \pm \text { SD }\end{array}$ & $68.37 \pm 14.6$ & $66.92 \pm 13.9$ & $65.91 \pm 12.63$ & $66.44 \pm 11.03$ & 0.861 \\
\hline $\begin{array}{l}\text { Gender }(\mathrm{n}) \\
(\mathrm{M} / \mathrm{F})\end{array}$ & $23 / 15$ & $12 / 25$ & $13 / 9$ & $40 / 40$ & 0.07 \\
\hline \multicolumn{6}{|l|}{$\begin{array}{l}\text { Cause of admission } \\
(\mathrm{n} \%)\end{array}$} \\
\hline MI & $20(22)$ & $24(26.4)$ & $10(11)$ & $37(40.7)$ & 0.27 \\
\hline UA & $3(17.6)$ & $3(17.6)$ & $1(5.9)$ & $10(58.8)$ & $* 0.52$ \\
\hline $\mathrm{CHF}$ & $5(23.8)$ & $3(14.3)$ & $2(9.5)$ & $11(52.4)$ & $* 0.44$ \\
\hline $\mathrm{CAD}$ & $0(0)$ & $1(20)$ & $1(20)$ & $3(60)$ & $0.31 *$ \\
\hline GIB & $0(0)$ & $1(50)$ & $0(0)$ & $1(50)$ & $0.63 *$ \\
\hline CVA & $2(33.3)$ & $0(0)$ & $1(16.7)$ & $3(50)$ & $0.36^{*}$ \\
\hline $\mathrm{PE}$ & $4(9.5)$ & $10(23.8)$ & $4(9.5)$ & $24(57.1)$ & 0.11 \\
\hline Cardiogenic shock & $18(31.6)$ & $9(15.8)$ & $5(8.8)$ & 25 (43.9) & 0.11 \\
\hline $\mathrm{AF}$ & $8(34.8)$ & $2(8.7)$ & $7(30.4)$ & $6(26.1)$ & $0.09^{*}$ \\
\hline \multicolumn{6}{|l|}{$\begin{array}{l}\text { Underlying disease } \\
(\mathrm{n} \%)\end{array}$} \\
\hline COPD & $0(0)$ & $1(50)$ & $0(0)$ & $1(50)$ & $0.63 *$ \\
\hline $\mathrm{CRF}$ & $4(28.6)$ & $0(0)$ & $2(14.3)$ & $8(57.1)$ & $0.42 *$ \\
\hline CVA & $1(6.2)$ & $5(31.2)$ & $0(0)$ & $10(62.5)$ & $0.12 *$ \\
\hline $\mathrm{AF}$ & $5(26.3)$ & $4(21.1)$ & $5(26.3)$ & $5(26.3)$ & $0.34 *$ \\
\hline Diabetes & $9(15.3)$ & $13(22)$ & $3(5.1)$ & $34(57.6)$ & 0.04 \\
\hline CABG & $0(0)$ & $2(50)$ & $0(0)$ & $2(50)$ & $0.4^{*}$ \\
\hline Pacemaker & $0(0)$ & $1(25)$ & $0(0)$ & $3(75)$ & $0.4^{*}$ \\
\hline HLP & $1(12.5)$ & $2(25)$ & $0(0)$ & $5(62.5)$ & $0.48^{*}$ \\
\hline HTN & $8(15.1)$ & $12(22.6)$ & $4(7.5)$ & $29(54.7)$ & 0.2 \\
\hline $\mathrm{CHF}$ & $14(26.4)$ & $12(22.6)$ & $6(11.3)$ & $21(39.6)$ & 0.67 \\
\hline $\mathrm{HCM}$ & $1(33.3)$ & $2(66.7)$ & $0(0)$ & $0(0)$ & $0.5^{*}$ \\
\hline Asthma & $1(33.3)$ & $0(0)$ & $1(33.3)$ & $1(33.3)$ & $0.5^{*}$ \\
\hline Opium addiction & $3(20)$ & $1(6.7)$ & $0(0)$ & $11(73.3)$ & $0.52 *$ \\
\hline Smoking & $3(17.6)$ & $2(11.8)$ & $1(5.9)$ & $11(64.7)$ & $0.52 *$ \\
\hline CAD & $16(20.5)$ & 19(24.4) & $1(14.1)$ & $32(41)$ & 0.64 \\
\hline \multicolumn{6}{|l|}{$\begin{array}{l}\text { Cause of cardiac } \\
\text { arrest }(\mathrm{n} \%)\end{array}$} \\
\hline Cardiogenic shock & $12(26.1)$ & $10(21.7)$ & $6(13)$ & $18(39.1)$ & 0.76 \\
\hline Asystole & $11(28.2)$ & $9(23.1)$ & $2(5.1)$ & $17(43.6)$ & 0.34 \\
\hline VF & $8(25.8)$ & $5(16.1)$ & $5(16.1)$ & $13(41.9)$ & 0.74 \\
\hline VT & $5(35.7)$ & $4(28.6)$ & $1(7.1)$ & $4(28.6)$ & $* 0.17$ \\
\hline Apnea & $20(17.7)$ & $23(20.4)$ & $15(13.3)$ & $55(48.7)$ & 0.37 \\
\hline Bradycardia & $24(20.2)$ & $24(20.2)$ & $16(13.4)$ & $55(46.2)$ & 0.86 \\
\hline
\end{tabular}

- $\quad$ *Due to lack of Hypothesis for Chi-Square Test, after merging the groups of non-holiday evening (2), Holidays (3) and Night (4) as the group of holidays and morning of non-holiday as the non-holiday group, Fisher Exact Test was done and the results were reported.

- $\quad$ Time of Admittance of 8 patients and time of CPR of 3 Patients was Unknown.

- MI: myocardial infarction, UA: unstable angina, CHF: congestive heart failure, CAD: coronary artery disease, GIB: gastrointestinal bleeding, CVA: cerebrovascular accident, PE: pulmonary embolism, AF: atrial fibrillation, COPD: chronic obstructive pulmonary disease, CRF: chronic renal failure, CABG: Coronary artery bypass graft, HLP: hyperlipidemia, HTN: Hypertension, HCM: hypertrophic cardiomyopathy, VF: ventricular arrhythmias, VT: ventricular tachycardia

admission for majority of them were in off duty hours. These times include the evening and night shifts of regular days, official holidays, and weekends. Day and the time of admittance in those times had a linear relationship with worsen 
Table 2 Distribution of cause of admission and underlying disease of expired patients in CCU in different time of CPR

\begin{tabular}{|c|c|c|c|c|c|}
\hline \multirow[b]{2}{*}{ Parameters } & \multicolumn{4}{|c|}{ CPR Time } & \multirow[t]{2}{*}{$P$ value } \\
\hline & $\begin{array}{c}1 \\
(\mathbf{N}=39)\end{array}$ & $\begin{array}{c}2 \\
(N=22)\end{array}$ & $\begin{array}{c}3 \\
(N=25)\end{array}$ & $\begin{array}{c}4 \\
(\mathbf{N}=96)\end{array}$ & \\
\hline $\begin{array}{l}\text { Age (years) } \\
\text { Mean } \pm \text { SD }\end{array}$ & $67.56 \pm 1259$ & $67 \pm 17.04$ & $63.88 \pm 10.66$ & $67.67 \pm 11.91$ & 0.6 \\
\hline $\begin{array}{c}\text { Gender (n) } \\
\text { M/F }\end{array}$ & $21 / 18$ & $13 / 9$ & $13 / 12$ & $45 / 51$ & 0.72 \\
\hline \multicolumn{6}{|l|}{$\begin{array}{c}\text { Cause of admission } \\
(\mathrm{n} \%)\end{array}$} \\
\hline MI & $18(19.4)$ & $11(11.8)$ & $14(15.1)$ & $50(53.8)$ & 0.88 \\
\hline UA & $1(5.9)$ & $1(5.9)$ & $6(35.3)$ & $9(52.9)$ & $0.09 *$ \\
\hline CHF & $3(14.3)$ & $3(14.3)$ & $2(9.5)$ & $13(61.9)$ & $0.31^{*}$ \\
\hline CAD & $1(20)$ & $0(0)$ & $0(0)$ & $4(80)$ & $0.72 *$ \\
\hline GIB & $0(0)$ & $0(0)$ & $1(50)$ & $1(50)$ & $0.62 *$ \\
\hline CVA & $0(0)$ & $1(16.7)$ & $1(16.7)$ & $4(66.7)$ & $0.24 *$ \\
\hline $\mathrm{PE}$ & $9(20.9)$ & $4(9.3)$ & $4(9.3)$ & $26(60.5)$ & 0.61 \\
\hline Cardiogenic shock & $20(33.9)$ & $6(10.2)$ & $7(11.9)$ & $26(44.1)$ & 0.04 \\
\hline $\mathrm{AF}$ & $5(20.8)$ & $2(8.3)$ & $4(16.7)$ & $13(54.2)$ & 0.92 \\
\hline \multicolumn{6}{|l|}{ Under disease ( $\mathrm{n} \%$ ) } \\
\hline COPD & $0(0)$ & $0(0)$ & $1(50)$ & $1(50)$ & $0.62 *$ \\
\hline CRF & $7(43.8)$ & $3(18.8)$ & $0(0)$ & $6(37.5)$ & $0.03^{*}$ \\
\hline CVA & $3(18.8)$ & $1(6.2)$ & $3(18.8)$ & $9(56.2)$ & $0.55^{*}$ \\
\hline $\mathrm{AF}$ & $5(26.3)$ & $1(5.3)$ & $2(10.5)$ & $11(57.9)$ & $0.37 *$ \\
\hline Diabetes & $13(22)$ & $5(8.5)$ & $10(16.9)$ & $31(52.5)$ & 0.66 \\
\hline CABG & $1(25)$ & $0(0)$ & $0(0)$ & $3(75)$ & $0.62 *$ \\
\hline Pacemaker & $0(0)$ & $0(0)$ & $1(25)$ & $3(75)$ & $0.39^{*}$ \\
\hline HLP & $2(25)$ & $0(0)$ & $1(12.5)$ & $5(62.5)$ & $0.53 *$ \\
\hline HTN & $10(18.9)$ & $6(11.3)$ & $9(17)$ & $28(52.8)$ & 0.84 \\
\hline $\mathrm{CHF}$ & $11(20.8)$ & $5(9.4)$ & $3(5.7)$ & $34(64.2)$ & 0.12 \\
\hline $\mathrm{HCM}$ & $0(0)$ & $1(33.3)$ & $0(0)$ & $2(66.7)$ & $0.48^{*}$ \\
\hline Asthma & $0(0)$ & $0(0)$ & $1(33.3)$ & $2(66.7)$ & $0.49^{*}$ \\
\hline Opium addiction & $5(29.4)$ & $2(11.8)$ & $2(11.8)$ & $8(47.1)$ & $0.27 *$ \\
\hline Smoking & $5(29.4)$ & $0(0)$ & $4(23.5)$ & $8(47.1)$ & $0.27 *$ \\
\hline CAD & $15(19.2)$ & $4(5.1)$ & $10(12.8)$ & $49(62.8)$ & 0.04 \\
\hline \multicolumn{6}{|l|}{$\begin{array}{c}\text { Cause of cardiac } \\
\text { arrest (n\%) }\end{array}$} \\
\hline Cardiogenic shock & $16(34.8)$ & $6(13)$ & $3(6.5)$ & $21(45.7)$ & 0.04 \\
\hline Asystole & $14(35.9)$ & $2(5.1)$ & $5(12.8)$ & $18(46.2)$ & 0.06 \\
\hline VF & $6(18.2)$ & $5(15.2)$ & $4(12.1)$ & $18(54.5)$ & 0.89 \\
\hline VT & $3(20)$ & $3(20)$ & $1(6.7)$ & $8(53.3)$ & $0.61 *$ \\
\hline Apnea & 19 (16.4) & $14(12.1)$ & $20(17.2)$ & $63(54.3)$ & 0.08 \\
\hline Bradycardia & $24(19.8)$ & $12(9.9)$ & $19(15.7)$ & 66 (54.5) & 0.38 \\
\hline
\end{tabular}

- Due to lack of hypothesis for Chi-Square Test, after merging the groups of non-holiday evening (2), holidays (3) and night (4) as the group of holidays and morning of non-holiday as the non-holiday group, Fisher Exact Test was done and the results were reported.

clinical outcome in these patients. These results were compatible with many prior researches (1318). The effect of weekends for patients with critical conditions that need multiple intensive interventions at the same time is of special importance. This problem was discussed in various researches and same results as our study were obtained (19-21). Many MI patients during
15 years studied and it was demonstrated that patients who were admitted at the weekends have higher mortality rate. This research showed that higher mortality at weekends in patients with a first myocardial infarction represents about 10 additional deaths per 1000 admissions per year. A higher mortality rate on weekends is for MI patients with less invasive procedures and delay in treatment (19). In a research that 86748with in 
Table 3 Association between time of admission with factors of cause of admission and underlying disease of expired patients in $\mathrm{CCU}$

\begin{tabular}{|c|c|c|c|}
\hline Variable & Odds ratio (OR) & \%95 CI & P value \\
\hline PE & 3.32 & $1.11-9.94$ & 0.032 \\
\hline Cardiogenic shock & 2.05 & $0.96-4.37$ & $0.06(0.96-4.37)$ \\
\hline AF & 2.45 & $0.92-6.54$ & $0.07(0.92-6.54)$ \\
\hline
\end{tabular}

- Binary Logistic Regression (Backward Stepwise) was performed. Factors entered in eth model: gender, PE, C. Shock, AF, CVA, DM and HTN.

Table 4 Association between time of CPR with factors of cause of admission and underlying disease of expired patients in $\mathrm{CCU}$

\begin{tabular}{l|l|l|l|}
\hline \multicolumn{1}{|c|}{ Variable } & Odds ratio (OR) & \%95 CI & P value \\
\hline cardiogenic shock & 3.31 & $1.53-7.14$ & 0.002 \\
\hline CRF & 4.78 & $1.51-15.15$ & 0.008 \\
\hline Asystole & 3.08 & $1.34-7.09$ & 0.008 \\
\hline
\end{tabular}

- Binary Logistic Regression (Backward Stepwise) was performed. Factors entered in eth model: UA, C.Shock, CRF, Asystole, Apnea, CHF and CAD.

hospital cardiac arrest patients in 7 years were evaluated, it was determined that survival rates were substantially lower during nights and weekends there is a less survival rates, except emergency department and trauma services that they often have similar staffing numbers and capabilities throughout the day, evening and night (20). Evaluation of mortality after admitting to emergency department that was done in 2003 study, suggests that deaths happen more in nonworking hours, at night and when the personnel are less or more tired (22). In a retrospective cohort study on the association between day hospital presentation and the quality and safety of stroke care were studied and showed that stroke patients that are admitted on weekends are less likely to receive urgent treatments and had higher mortality rate. The proposed solutions to address the weekend effect such as maintaining more consistent levels of activity during these time, which can be economical even if hospital staff are paid at higher levels (23). The results of a large, multicenter study on emergency admissions at the same time showed that risk of mortality in patients admitted on weekends are $10 \%$ more than week day's admissions (24). This problem was also seen in Acute Kidney Injury patients admitted on weekends (9). Recently mortality rate of patients with different diagnoses according to weekend and week day admissions were studied and demonstrated that patient with Cardiac arrest or serious Arrhythmia had significantly higher mortality rate on weekends (25). In another study that emergency admissions in 11 years were studied it was determined that the mortality for weekend admissions was higher than that for weekday admissions. In this study the effect of admission at weekends on mortality remained much the same throughout the 11- year period study (11). A study on the relationship between time of day, day of week and duration of treatment procedures and in-hospital mortality for patients with acute ST- segment elevation myocardial infarction showed that presentation 
during off-hours was associated with substantially longer times to treatment for percutaneous coronary intervention (PCI) but not for fibrinolytic therapy. Also patients treated on off-hours had higher mortality rate compare to those on regular hours (26). There also have been more reports the existence of greater mortality risk for emergency PCI performed at night than for day time (27). This study determined that $80 \%$ of expired patients admitted on unofficial (off) hours and holidays and the most mortality rate were for the patients admitted at night shifts that for the patients with DM as comorbidity this difference was statistical significant. The most important causes of death in patients admitted to emergency department are, delays in doctor's visit, inaccurate diagnoses, delays in investigations and initiation of treatment; they occurred mostly in those admitted at night, when there are fewer personnel or more tired they are (22). Also results of our study shows that most of expired patients in holidays and unofficial hours had CPR and this was even more in night shift and the difference was statistical significant in patients with Coronary Artery Disease (CAD) and Chronic Renal Failure (CRF) and also patients that their cause of admission or cardiac arrest were cardiogenic shock. Our results are compatible with other studies: CPR performance after cardiac arrest at night shift was associated with higher mortality rate and shorter survival in comparison with morning and evening shifts (28). In this study after adjusting other variables, it was determined that patients admitted due to pulmonary embolism (PE) in holidays are 3.3 times more than non holidays, as well as patients admitted because of CRF, their CPR on holidays are 4.78 times higher than non-holidays, patients that cardiogenic shock brought them to hospital, their CPR was 3.3 times more on holidays; CPR done on patients that their cause of death were asystole were 3.08 times more on holidays. An important nursing activity in the coronary care unit (CCU) is assessing trends in a patient's hemodynamic parameters, vital signs and Lab tests and ECG data (29). Evidence suggests an inverse link between the number of nurses, patient mortality and length of stay. A patient in crisis is in need of intervention and specialist support 24 hours a day and there is evidence that patients admitted overnight have a higher risk of mortality. Also there is a direct association between number staffing levels and patient outcomes and higher standard of care from nurse lowers mortality in hospital (30).

Possible factors involving higher mortality of patients on weekends include, fewer personnel, changes in attendance of physicians and fewer specific diagnostic and treating procedures on these times; since the fewer personnel and doctors on weekends causes the less experienced ones to take responsibility of more work load that lead to higher mortality in patients admitted in these times (8). Our study contrary to the recent study that divided patients in two groups admitted on weekends and week days (12), considered admission in night and other holidays as non working hours that have higher mortality rate. Limitations of our study were that we had not enough data on personnel and doctors on duty on different hours. Also it was not observed an accurate data on different diagnostic and treating procedures done on patients in different hours. The other issue was that we only entered expired patients and did not compare to patients released from CCU.

\section{Conclusion}

Considering the results of study, higher mortality of CCU patients that admitted or performed $\mathrm{CPR}$ on them during night, un official hours and holidays shows that patient care and diagnostic and treating procedures in these times at this hospital are not done effectively; and this issue could rise from fewer doctors, nurses or tiredness of staff at night hours. Therefore to reduce this problem we suggest the use of more personnel, more experienced and skilled at these times.

\section{Acknowledgements}

The authors would like to thanks the nurses and patients of CCU of Noor's general hospital for their collaborations.

\section{Conflict of interest statement}

The authors claim that they have no conflicting interest in this study. 


\section{References}

1. Michalopoulou A, Tsios A, Vitos M, Liapi P, Mpizas L. admissions to the coronary care unit (CCU): comparison with international data. Hospital Chronicles 2008;3:182-6.

2. Berger A, Stauffer JC, Radovanovic D, Urban P, Bertel O, Erne P. comparison of in-hospital mortality for acute myocardial infarction in Switzerland with admission during routine duty hours versus admission during out of hours. Am J Cardiol 2008; 101:422-7.

3. Schenarts $\mathrm{P}$, Bowen $\mathrm{J}$, Bard $\mathrm{M}$, Sagraves $\mathrm{S}$, Toschlog E, Goettler C, et al. The effect of a rotating night-float coverage scheme on preventable and potentially preventable morbidity at a level 1 trauma center. Am J Surgery 2005;190:147-52.

4. Lee SK, Lee DC, Andrews W L, Baboolal R, Pendray M, Stewart S, Higher mortality rates among inborn infants admitted to neonatal intensive care units at night. J Pediatr 2003; 143:592-7.

5. Barba R, Losa J.E, Velasco M, Guijarro C, Garcı'a de Casasola G, Zapatero A. Mortality among adult patients admitted to the hospital on weekends. Euro J Inter Med 2006;17:322-4.

6. Ananthakrishnan AN, Mcginley EL, Saeian K. Outcomes of weekend admissions for upper gastrointestinal hemorrhage: a nationwide analysis. Clin Gastrol Hepatol 2009;7:296-302.

7. Lairez O, Roncalli J, Carrié D, Elbaz M, Galinier M, Tauzin S, et al. Relationship between time of day, day of the wee and in-hospital mortality in patients undergoing emergency percutaneous coronary intervention. Arch Cardiovasc Dis 2009; 102:811-20.

8. Ricciardi R, Nelson J, Roberts PL, Marcello PW, Read TE, Schoetz DJ. Is the presence of medical trainees associated with increased mortality with weekend admission? BMC Med Educ 2014; $14: 4$.

9. James MT, Wald R, Bell CM, Tonelli M, Hemmelgarn BR, Waikar S, Chertow GM. Weekend hospital admission, acute kidney injury, and mortality. J Am Soc Nephrol 2010; 21:845-51

10. Arias Y, Taylor D.S, Marcin J.P. Association between evening admissions and higher mortality rates in the pediatric intensive care unit. Pediatrics 2004;113:530-4.

11. Handel AE, Patel SV, Skingsley A, Bramley K, Sobieski R, Ramagopalan SV. Weekend admissions as an independent predictor of mortality: an analysis of Scottish hospital admissions. BMJ 2012;2:1-8.

12. Hamaguchi S, Kinugawa Sh, Tsuchihashi-Makaya M, Goto D, Tsutsui H. Weekend versus weekday hospital admission and outcome during hospitalization for patients due to worsening heart failure: a report from Japanese Cardiac Registry of Heart Failure In Cardiology (JCARE-CARD). Heart Vessels 2014;29:328-35.

13. MGallerani M, Imberti $D$, Bossone E, Eagle KA, Manfredini R. Higher mortality in patients hospitalized for acute aortic rupture or dissection during weekends. J Vascular Surgery 2012;55: 1247-54.
14. Schneider B, HiraniS A, Hambridge HL, Haut E $\mathrm{R}$, Carlini AR, Castillo RC, et al. Beating the weekend trend: Increased mortality in older adult Traumatic brain injury (TBI) patients admitted on weekends. J Surg Res 2012;177:295-300.

15. Marco J, Barba R, Plaza S, Losa JE, Canora J, Zapatero A. Analysis of the mortality of patients admitted to internal medicine wards over the weekend. Am J Med Qual 2010;25:312-8.

16. Fang J, Saposnik G, Silver FL, Kapral MK. Association between weekend hospital presentation and stroke fatality. Neurology 2010; 75:1589-96.

17. Deshmukh A, PantS, Kumar G, Bursac Z, Paydak H, Mehta JL. Comparison of outcomes of weekend versus weekday admissions for atrial fibrillation. Am J Cardiol 2012;110:208-11.

18. Sharp AL, Choi H, Hayward RA. Don't get sick on the weekend: an evaluation of the weekend effect on mortality for patients visiting US EDs. Am J Emerg Med 2013;31:835-7.

19. Kostis WJ, Demissie K, Marcella SW, Shao Yu$\mathrm{H}$, Wilson AC, Moreyra AE, Weekend versus weekday admission and mortality from myocardial infarction. N Engl J Med 2007; 356:1099-109.

20. Peberdy MA, Ornato JP, Larkin GL, Braithwaite RS, Kashner TM, Carey SM, et al. Survival from in-hospital cardiac arrest during nights and weekends. J Am Med Association (JAMA) 2008; 299:785-92.

21. Saposnik G, Baibergenova A, Bayer N, Hachinski V. Weekends: A dangerous time for having a stroke. Stroke 2007; 38:1211-5.

22. Seward E, Greig E, Preston S, Harris RA, Borrill Z, Wardle TD, et al. A confidential study of deaths after emergency medical admission: issues related to quality of care. Clin Med 2003; 3:425-34.

23. Palmer WL, Bottle A, Davie $\mathrm{Ch}$, Vincent CA, Aylin P. Dying for the Weekend: A retrospective cohort study on the association between day of hospital presentation and the quality and safety of stroke care. Arch Neurol 2012;69:1296-1302.

24. Aylin P, Yunus A, Bottle A, Majeed A, Bell D. Weekend mortality for emergency admissions. A large, multicentre study. Qual Saf Health Care 2010;19:213-7.

25. Concha OP, Gallego B, Hillman K, Delaney GP, Coiera E. Do variations in hospital mortality patterns after weekend admission reflect reduced quality of care or different patient cohorts? A population-based study. BMJ Qual Saf 2014; 23:215-22.

26. Magid DJ, Wang $Y$, Herrin $J$, McNamara RL, Bradley EH, Curtis JP, et al. Relationship between time of day, day of week, timeliness of reperfusion, and in hospital mortality for patients with acute st-segment elevation myocardial infarction. J Am Med Association (JAMA) 2005; 294:803-12.

27. Laireza O, Roncalli J, Carriéa D, Elbaza M, Galinier M, Tauzina S, et al. Relationship between time of day, day of the week and inhospital mortality in patients undergoing 
emergency percutaneous coronary intervention. Arch Cardiovascular Dis 2009;102:811-20.

28. Matota I, Shleifer A, Herschc M, Lotand Ch, Weinigera $\mathrm{CF}$, Drore $\mathrm{Y}$, et al. In-hospital cardiac arrest: Is outcome related to the time of arrest? Resuscitation 2006;71:56-64.

29. Pelter MM, Adams MG, Wung ShF, Paul SM, Drew BJ, Peak time of occurrence of myocardial ischemia in the coronary care unit. Am $\mathrm{J}$ Crit Care 1998;7:411-7.

30. British cardiovascular society. From coronary care unit to acute cardiac care unit- the evolving role of specialist cardiac cares 2011. https://www.bcs.com/documents/9a6_bcs_report _on_coronary_care_units.pdf. 